\title{
ISOLATION AND LOCALIZATION OF AN IRON-BINDING RABBIT SEMINAL PLASMA ANTIGEN
}

\author{
M. G. O'RAND \\ Institute for Molecular and Cellular Evolution, University of Miami, \\ 521 Anastasia Avenue, Coral Gables, Florida 33134, U.S.A.
}

(Received 5th November 1973)

\begin{abstract}
Summary. An iron-binding protein (IBP) is present in rabbit ejaculates. The IBP was isolated from rabbit ejaculates by ion-exchange and Sephadex G-100 chromatography. It had the electrophoretic mobility of a slow $\beta$-globulin and an approximate molecular weight of $105,000 \pm$ 10,000 . Using specific antibodies, IBP was detected in seminal plasma from vasectomized males but not in epididymal sperm supernatants or extracts. Further, IBP could be localized on seminal particles by immunofluorescence microscopy and exchange agglutination. Rabbit IBP could not be detected on the surface of ejaculated or epididymal spermatozoa.
\end{abstract}

\section{INTRODUCTION}

Mammalian sperm surface antigens are either intrinsic or 'coating' antigens (Weil \& Rodenburg, 1962). Seminal plasma (Chang, 1957) or isolated spermcoating antigens (Hunter \& Nornes, 1969) can block fertilization and one or more such antigens may be removed during capacitation (Johnson \& Hunter, 1972). The decapacitation factor found in seminal plasma (Williams, Abney, Chernoff, Dukelow \& Pinsker, 1967) may also be a surface antigen which is removed or modified during capacitation. However, studies concerned with the isolation and fractionation of seminal plasma antigens (Hunter \& Nornes, 1969; Zappi, Smith \& Shulman, 1972; Li \& Beling, 1973) have not been combined with the localization of that particular antigen on the spermatozoon.

Lactoferrin has been described as a human sperm-coating antigen (Hekman \& Rumke, 1969) as has the iron-binding protein, scaferrin, which differs from lactoferrin in its electrophoretic mobility (Roberts \& Boettcher, 1969). Neither lactoferrin nor scaferrin has been isolated from seminal plasma. In the rabbit, lactoferrin has only been identified in heterophil leucocytes (Baggiolini, DeMuve, Masson \& Heremans, 1970). Rabbit milk predominantly contains transferrin which differs from rabbit serum transferrin in its sialic acid content (Baker, Shaw \& Morgan, 1968). Rabbit transferrin has been reported to contain one (Hudson, Ohno, Brockway \& Castellino, 1973) and two sub-units (Baker et al., 1968).

The present results indicate that an iron-binding protein (IBP) is present in rabbit ejaculates. The IBP has the electrophoretic mobility of a slow $\beta$-globulin 
and an approximate molecular weight of $105,000 \pm 10,000$. By the use of specific antibodies, this protein has been detected in the seminal plasma of vasectomized males but not in epididymal sperm supernatants or extracts. Unlike human lactoferrin (Hekman \& Rumke, 1969), this IBP could not be detected on the surface of ejaculated spermatozoa although it was present on seminal plasma particulate matter (Metz, Hinsch \& Anika, 1968). These results illustrate that a careful distinction must be made between ejaculated spermatozoa and ejaculated seminal plasma particulate matter when the designation 'spermcoating antigen' is applied to antigens isolated from rabbit ejaculates.

\section{MATERIALS AND METHODS}

Rabbit ejaculates were collected from New Zealand white rabbits of known fertility with an artificial vagina. Seminal solids (Metz et al., 1968), i.e. spermatozoa, leucocytes, and several types of particles, were removed by centrifugation at $3000 \mathrm{~g}$ and the supernatant was collected. The seminal solids were washed with 1 vol. of phosphate-buffered saline (PBS, 0.01 m-phosphate, $\mathrm{pH}$ 7.0 ) equal to the volume of the first supernatant and recentrifuged. This was repeated once more for the protein isolation procedure. All the supernatants were pooled and stored frozen until use.

After the collection of sufficient ejaculate supernatant, the IBP /was isolated using a modification of the methods described for rabbit milk and serum transferrin (Baker et al., 1968). Globulins were precipitated with $21.5 \%$ sodium sulphate for $2 \mathrm{hr}$ at $37^{\circ} \mathrm{C}$. Following centrifugation at $12,500 \mathrm{~g}$ for $10 \mathrm{~min}$, the supernatant was dialysed first against distilled water for $48 \mathrm{hr}$ with several changes and then against tris-HCl buffer $(0.05 \mathrm{M}, \mathrm{pH} 8.6)$ for $24 \mathrm{hr}$ with two changes. To remove the low molecular weight contaminants, the non-dialysable material was passed through a $2.4 \times 40 \mathrm{~cm}$ Sephadex G-25 column equilibrated with the same buffer. The void volume was collected and applied to a $2 \cdot 4 \times 40 \mathrm{~cm}$ DEAE Sephadex A-50 column. The column was initially equilibrated with tris-HCl buffer $(0.05 \mathrm{M}, \mathrm{pH} 8.6)$, and the sample was then applied and eluted with a linear salt gradient from $0.05 \mathrm{M}$-tris- $\mathrm{HCl}, \mathrm{pH} 8.6$, to $0.4 \mathrm{M}$-tris- $\mathrm{HCl}$, $\mathrm{pH} \mathrm{7.0.}$

Gel filtration on Sephadex G-100 (1.5 $\times 90 \mathrm{~cm}$ column) was used to achieve further purification of the ion-exchange peak and estimate the molecular weight.

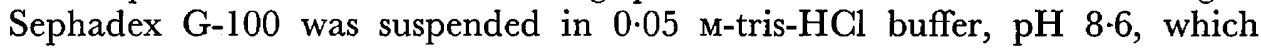
contained $0.5 \mathrm{M}$-sodium chloride. The sample was eluted in this buffer. To estimate the molecular weight, the column was calibrated with ribonuclease A (mol. wt 13,700), chymotrypsinogen (mol. wt 25,000), ovalbumin (mol. wt 45,000), and aldolase (mol. wt 158,000), from Pharmacia, and the sample was compared with the standards (Whitaker, 1963; Andrews, 1965). Blue dextran 2000 (Pharmacia) was used to establish the void volume.

Disc gel electrophoresis was carried out in $7.5 \%$ polyacrylamide gels in a tris-glycine buffer, $\mathrm{pH} 8.3$. Sodium dodecyl sulphate (SDS) polyacrylamide electrophoresis was also employed to check the purity of the sample. Before SDS electrophoresis, the protein samples were incubated in 5 M-urea +0.002 M-iodoacetamide $+1 \%$ SDS for $1 \mathrm{hr}$ at $60^{\circ} \mathrm{C}$. 
Protein concentration was measured by the biuret method (Gornall, Bardawill \& David, 1949). The iron content was determined with 4,7-diphenyl1,10 phenanthroline (Scientific Products), using the method of Positano \& Wiesel (1958) except that hydroxylamine hydrochloride (Mallinckrodt, analytical reagent) was substituted for hydroxylammonium chloride. Ferric chloride in 0.005 N-hydrochloric acid was used as a standard (Morgan \& Carter, 1960).

To identify the IBP as an antigen, antisera prepared in goats (Metz \& Anika, 1970; Metz, Seiguer \& Castro, 1972) against rabbit epididymal spermatozoa, ejaculated whole semen, and seminal plasma from vasectomized males were used. Immunodiffusion was carried out on $2 \times 2$ in. plates in $1.5 \%$ agarose after the method of Ouchterlony (1962). Immunoelectrophoresis was

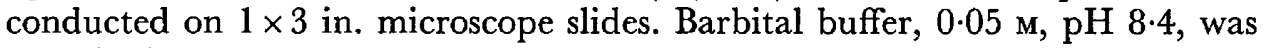
used for immunoelectrophoresis and immunodiffusion.

Specific antisera to the IBP (AIBP) were prepared in guinea-pigs by injection of $750 \mu \mathrm{g}$ of protein $(0.5 \mathrm{ml})$ with an equal volume of complete Freund's adjuvant, two injections at weekly intervals. On the $3 \mathrm{rd}$ week, the animals were bled by heart puncture. Antisera from six different animals were pooled and precipitated with $18 \% \mathrm{Na}_{2} \mathrm{SO}_{4}$ (Kekwick, 1940). Antisera to twice-washed ejaculated rabbit seminal solids were prepared in guinea-pigs (Metz et al., 1968).

The $\gamma$-globulin fraction of AIBP and from control animals injected with adjuvant and saline was labelled with fluorescein isothiocyanate (Nutritional Biochemicals) according to the method of Goldman (1968), passed through a Sephadex G-25 column and centrifuged at $3800 \mathrm{~g}$ to remove unconjugated dye and any precipitated material. The diffusion of conjugated antisera against IBP was studied in an immunodiffusion plate and, when checked for fluorescence, the single precipitin band fluoresced. Fluorescein-conjugated goat anti-rabbit whole semen $\gamma$-globulin (ARWS) served as a positive control. The control or immune (AIBP or ARWS) sera were allowed to react with either live spermatozoa or air-dried smears (Johnson \& Hunter, 1972). When live preparations were used, they were first layered onto a two-step sucrose gradient (a $0.3 \mathrm{M}$-sucrose bottom layer and a $0.15 \mathrm{M}$-sucrose top layer made in PBS, $\mathrm{pH} 7)$ and centrifuged (3000 g) to remove conjugated antibody, which had not reacted, from the spermatozoa before evaluation.

\section{RESULTS}

\section{Isolation}

Following ion-exchange chromatography, two protein peaks were detected (Text-fig. 1). Peak A appeared at approximately the $0.2 \mathrm{~m}$ concentration of tris-HCl buffer followed by a second peak (Peak B) at approximately the $0 \cdot 25$ m concentration. Peak A was concentrated and applied to a Sephadex G-100 column, resulting in the single peak, P1 (Text-fig. 2). Electrophoresis of this peak in $7.5 \%$ polyacrylamide gel gave one major band (Pl. 1, Fig. 1). A minor band frequently migrated slightly ahead of the major band, but rabbit serum transferrin (Miles Laboratory) migrated well ahead of Peak P1 under the same electrophoretic conditions (P1. 1, Fig. 1). The major electro- 


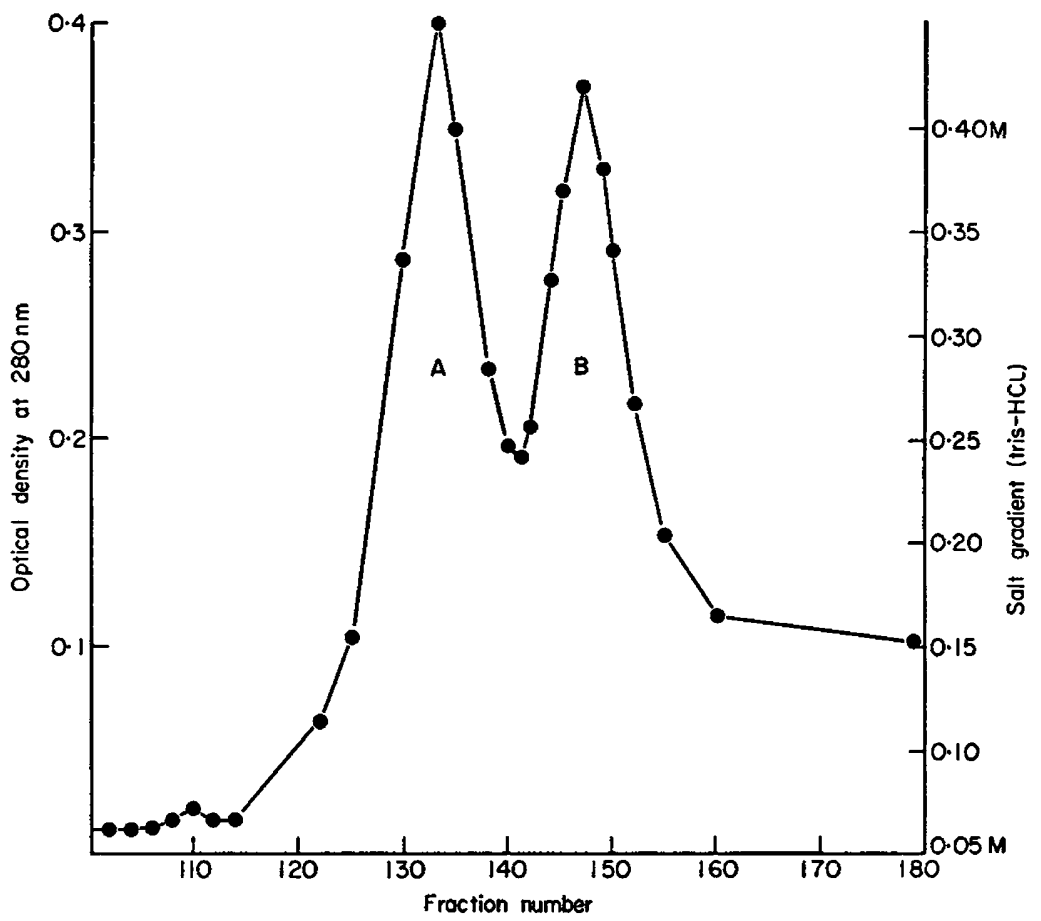

TexT-FIG. 1. DEAE-Sephadex A-50 column chromatography of rabbit ejaculate supernatant after precipitation with $21.5 \%$ sodium sulphate. -1 , absorbance at $280 \mathrm{~nm}$. Gradient from $0.05 \mathrm{M}$-tris- $\mathrm{HCl}, \mathrm{pH} 8.6$, to $0.4 \mathrm{M}$-tris-HCl, $\mathrm{pH} 7.0$.

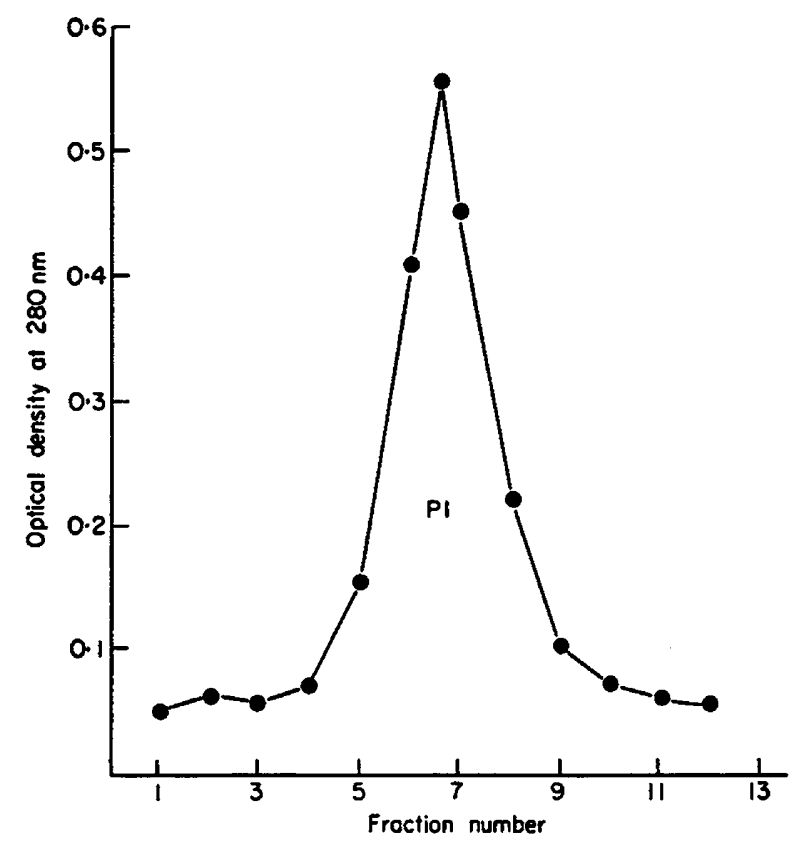

TexT-FIG. 2. Sephadex G-100 column chromatography of ion-exchange Peak A (Textfig. 1) with tris-HCl buffer, $0.05 \mathrm{M}, \mathrm{pH} 8 \cdot 6$, plus 0.5 M-sodium chloride. 


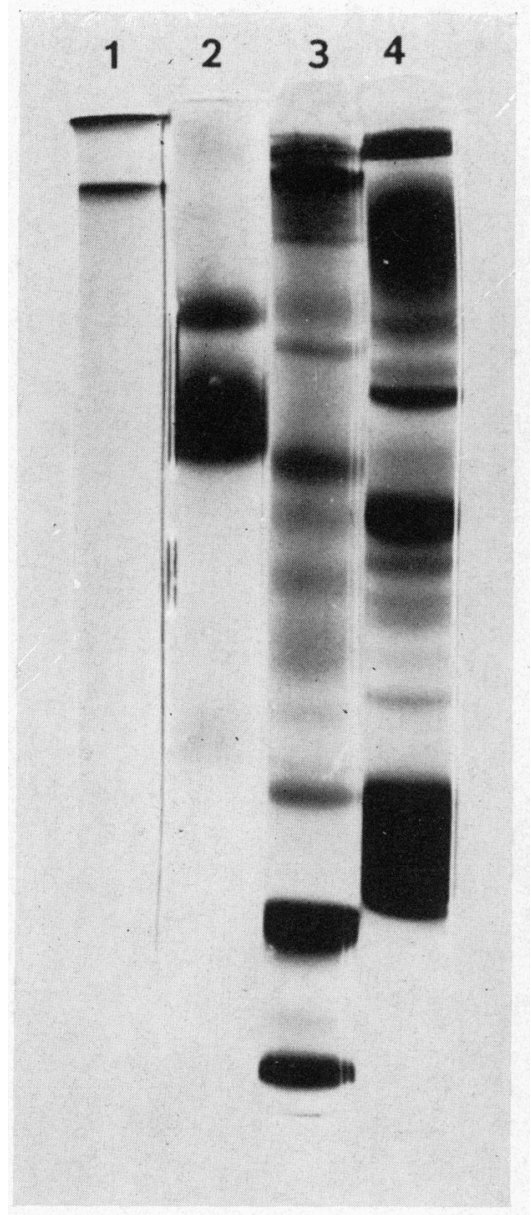

FIG. 1

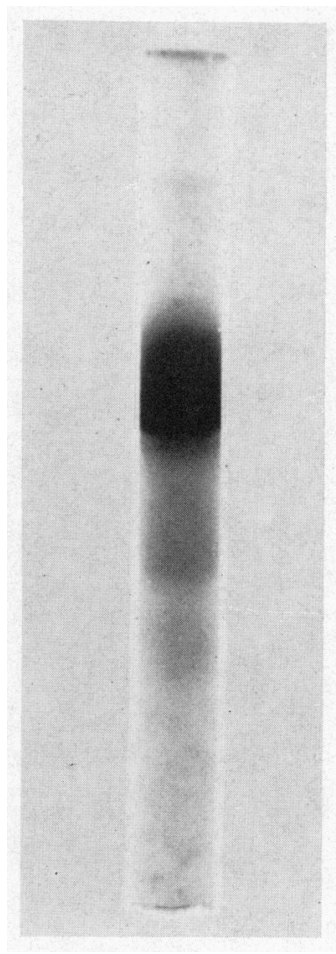

FIG. 2

Fig. 1. Electrophoresis in $7 \cdot 5 \%$ polyacrylamide gel, tris-glycine buffer, pH $8 \cdot 3$. Left to right: (1) Sephadex G-100 peak, P1, (2) commercial rabbit serum transferrin (Miles Laboratories), (3) rabbit whole ejaculate supernatant, (4) whole rabbit serum. Gels were run in separate experiments.

Fig. 2. Sodium dodecyl sulphate (SDS) polyacrylamide electrophoresis of Sephadex G-100 peak, P1. The protein was preincubated in $5 \mathrm{M}$-urea $+0.0022 \mathrm{M}$-iodoacetamide and $1 \%$ SDS for $1 \mathrm{hr}$ at $60^{\circ} \mathrm{C}$. 
PIATE 2

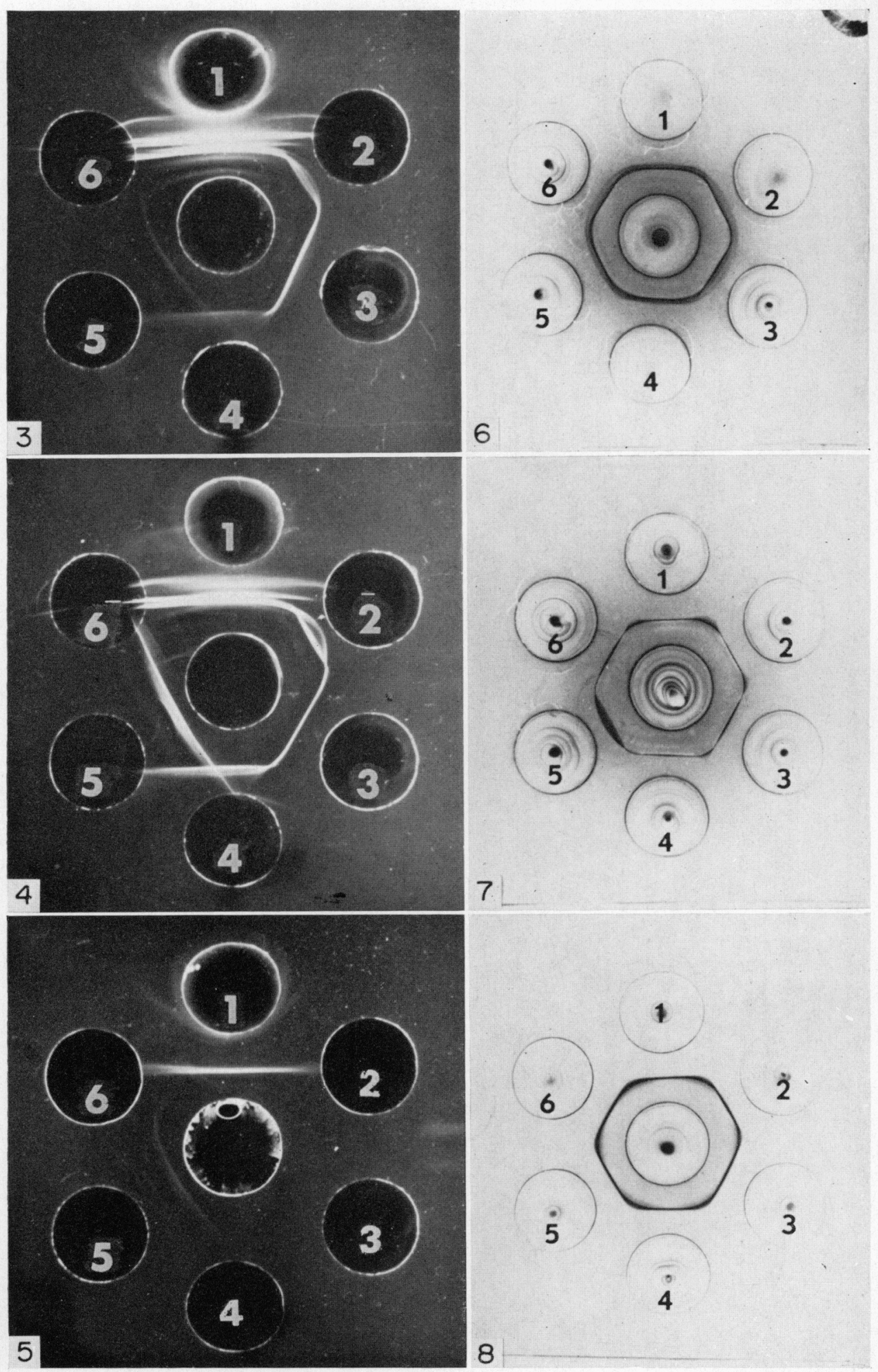


phoretic band of Peak P1 was present in rabbit whole ejaculate supernatant but did not appear as a clearly defined band in rabbit whole serum (Pl. 1, Fig. 1). After SDS gel electrophoresis, Peak P1 gave five bands (PI. 1, Fig. 2), one prominent band and several minor bands. Whether or not the other four bands represent breakdown products of $\mathrm{P} 1$ or contaminating protein has not been determined.

\section{Iron content}

The iron content of individual ejaculate supernatants varied considerably. In one protein isolation experiment, the ion-exchange Peak $A$ was found to contain $7.2 \mu \mathrm{g}$ iron $/ \mathrm{mg}$ protein, Peak B contained $0.3 \mu \mathrm{g}$ iron $/ \mathrm{mg}$ protein and the starting ejaculate supernatant contained $1.13 \mu \mathrm{g}$ iron $/ \mathrm{mg}$ protein. In another

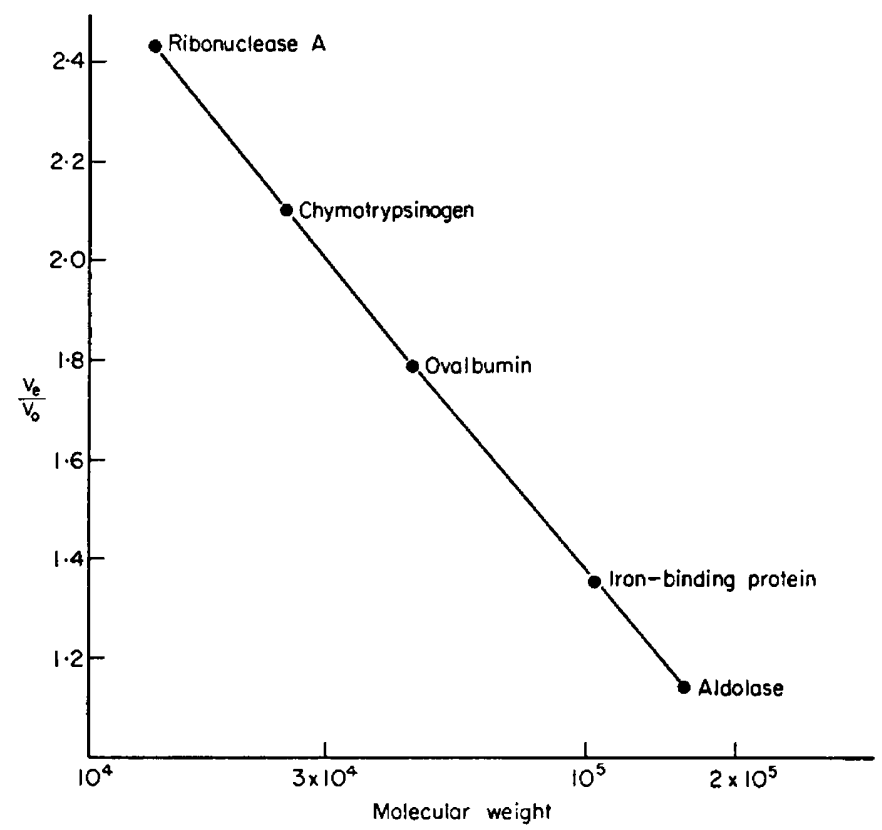

Text-FIG. 3. Molecular weight estimation of rabbit iron-binding protein from ejaculate supernatants by Sephadex G-100 gel filtration.

\section{EXPLANATION OF PLATE 2}

FIG. 3. Centre well: goat anti-rabbit whole semen.

Fig. 4. Centre well: goat anti-rabbit seminal plasma from vasectomized males.

FIG. 5. Centre well: goat anti-rabbit epididymal spermatozoa.

Figs 3, 4 and 5. Clockwise: Well 1: whole ejaculate supernatant; Well 2: ejaculate supernatant after $21.5 \% \mathrm{Na}_{2} \mathrm{SO}_{4}$ precipitation; Well 3: ion-exchange Peak A; Well 4: ion exchange Peak B; Well 5: normal rabbit serum; Well 6: normal rabbit serum after $21.5 \% \mathrm{Na}_{2} \mathrm{SO}_{4}$ precipitation.

Fig. 6. Centre well: goat anti-rabbit whole semen.

Fig. 7. Centre well: goat anti-rabbit seminal plasma from vasectomized males.

Fic. 8. Centre well: guinea-pig anti-rabbit iron-binding protein.

Figs 6, 7 and 8. Clockwise: Well 1: ion-exchange Peak A; Well 2: Sephadex G-100 Peak, P1; Well 3: ion-exchange Peak B; Well 4: ion-exchange Peak A; Well 5: ionexchange Peak A and B; Well 6: ion-exchange Peak B. 
isolation run, the Sephadex G-100 peak, P1, contained 7.8 $\mu \mathrm{g}$ iron/mg protein and the pooled ejaculate supernatants from which it was obtained contained $1.8 \mu \mathrm{g}$ iron/mg protein. A third run from an ejaculate supernatant pool of $0.45 \mu \mathrm{g}$ iron $/ \mathrm{mg}$ protein contained $2.3 \mu \mathrm{g}$ iron $/ \mathrm{mg}$ protein in Peak Pl.

\section{Molecular weight estimation}

The molecular weight of the protein present in Peak P1 (Text-fig. 2) was estimated by Sephadex G-100 chromatography. The results of the gel filtration are shown in Text-fig. 3. From calibration of the column, the molecular weight was found to be $105,000 \pm 10,000$.

\section{Immunology}

Immunodiffusion of Peaks A and B and the Sephadex G-100 peak, P1, against ARWS, goat anti-rabbit seminal plasma from vasectomized males (ARSP), and goat anti-rabbit epididymal spermatozoa (ARES) are shown in Plate 2. The ARWS and ARSP sera produced one major precipitin band with Peak A and one major and some minor bands with Peak B (Pl. 2, Figs 3 and 4). The ARES sera did not produce precipitin bands with any antigens in Peak A or B (Pl. 2, Fig. 5). The antigens of Peaks A and B are not present in normal rabbit serum (Plates 2, 3, 4 and 5). Furthermore, goat anti-rabbit whole serum (Microbiological Associates) did not produce any precipitin bands with Peaks A, B or P1.

The identical major precipitin band present in all three peaks (A, B and P1) was obtained with either ARWS or ARSP (Pl. 2, Figs 6 and 7). Antibodies from guinea-pigs injected with Peaks A and B produced only one precipitin band which formed a line of identity with bands from all three peaks (Pl. 2, Fig. 8). Thus, the guinea-pig antisera against Peak $A$ and $B$ is monospecific for the protein of peak P1 which is the iron-binding protein. Specific antisera AIBP did not produce any precipitin bands with normal rabbit serum, epididymal sperm supernatants or extracts.

Immunoelectrophoresis of Peak P1 and ejaculate supernatant with guinea-pig anti-rabbit twice-washed seminal solids as the diffusing antibody showed one precipitin band present in Pl (Pl. 3, Fig. 9). Peak Pl also showed one immunoelectrophoretic band with ARSP (P1. 3, Fig. 10).

Because rabbit ejaculates contain a variety of seminal particles (Metz et al., 1968) which sediment with spermatozoa during centrifugation and subsequent washings, it was of interest to determine whether the IBP could be removed from the ejaculate by washing. The AIBP sera produced a precipitin band with the IBP in the first whole ejaculate supernatant and very weakly in the supernatant after the sixth wash (see 'Materials and Methods' and Pl. 3, Fig. 11), but the sperm pellet obtained after six washings still contained the IBP (PI. 3, Fig. 12). The IBP present in the ejaculate supernatants and ejaculate pellets was present in the seminal plasma of vasectomized males and formed a line of identity with the P1 antigen band (Pl. 3, Figs 11 and 12).

\section{Localization of the IBP}

Ejaculated or epididymal spermatozoa in live or air-dried preparations did 


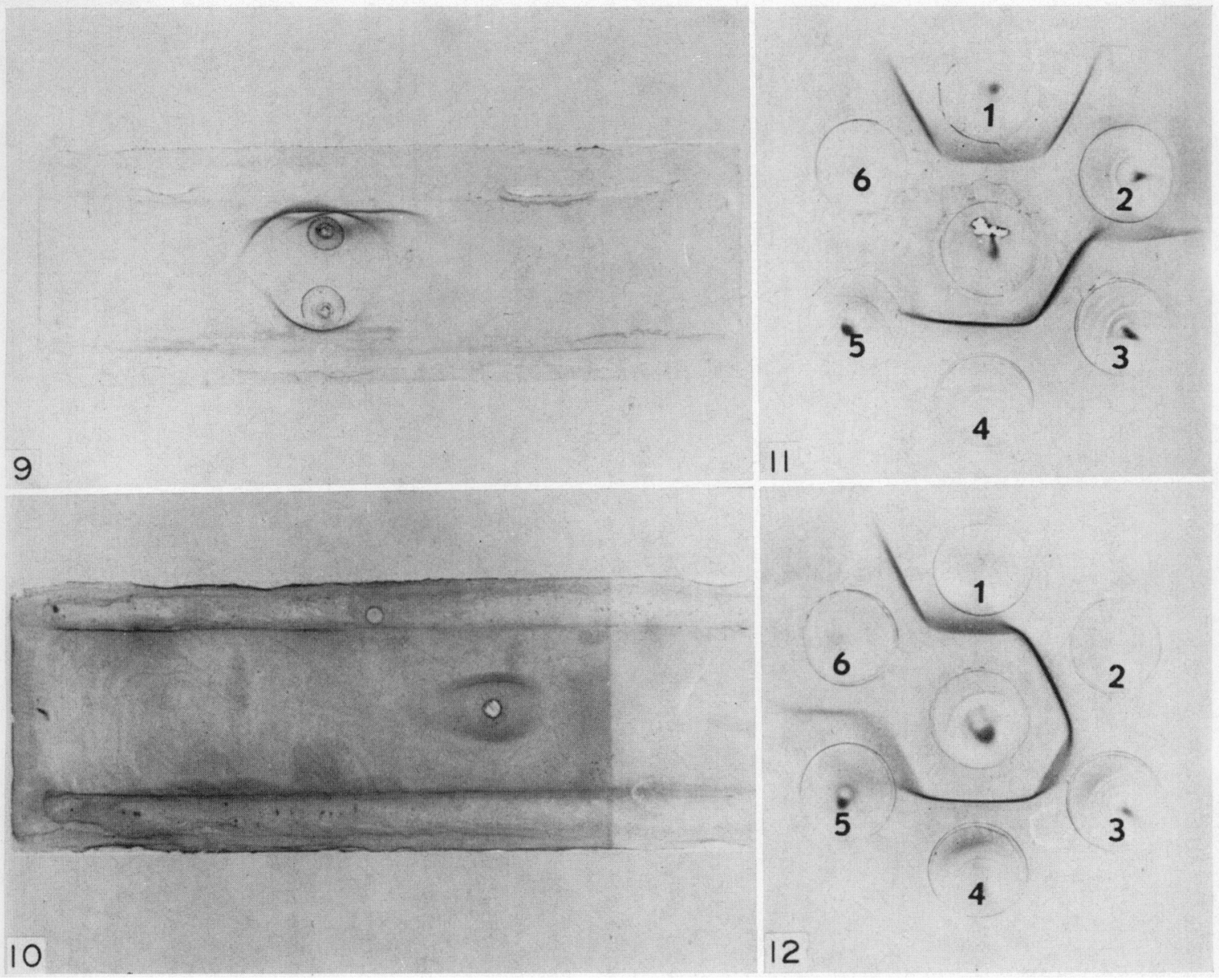

Fig. 9. Immunoelectrophoresis of rabbit ejaculate supernatant (upper hole) showing the results of diffusion of Peak PI (lower hole) against guinea-pig anti-rabbit twice-washed seminal solids.

FIG. 10. Immunoelectrophoresis showing the results of diffusion of Peak Pl, against goat anti-rabbit seminal plasma from vasectomized males.

FIGs 11 and 12. Centre well: guinea-pig anti-rabbit iron-binding protein (AIBP).

FIG. 11. Clockwise: Well 1: Peak PI; Well 2: AIBP diluted 1:2 with PBS; Well 3: freshly collected, first ejaculate supernatant diluted 1:6 with PBS; Well $4:$ seminal plasma from a vasectomized buck; Well 5: ejaculate supernatant after the sixth wash of the sperm pellet; Well 6: AIBP, undiluted.

Fig. 12. Clockwise: Well 1: Peak P1; Well 2: freshly collected, first and second ejaculate supernatant, undiluted; Well 3: ejaculate sperm pellet from first supernatant plus six drops of PBS; Well 4: seminal plasma from a vasectomized buck; Well 5: ejaculate sperm pellet from sixth supernatant plus six drops of PBS; Well 6: AIBP, undiluted. 


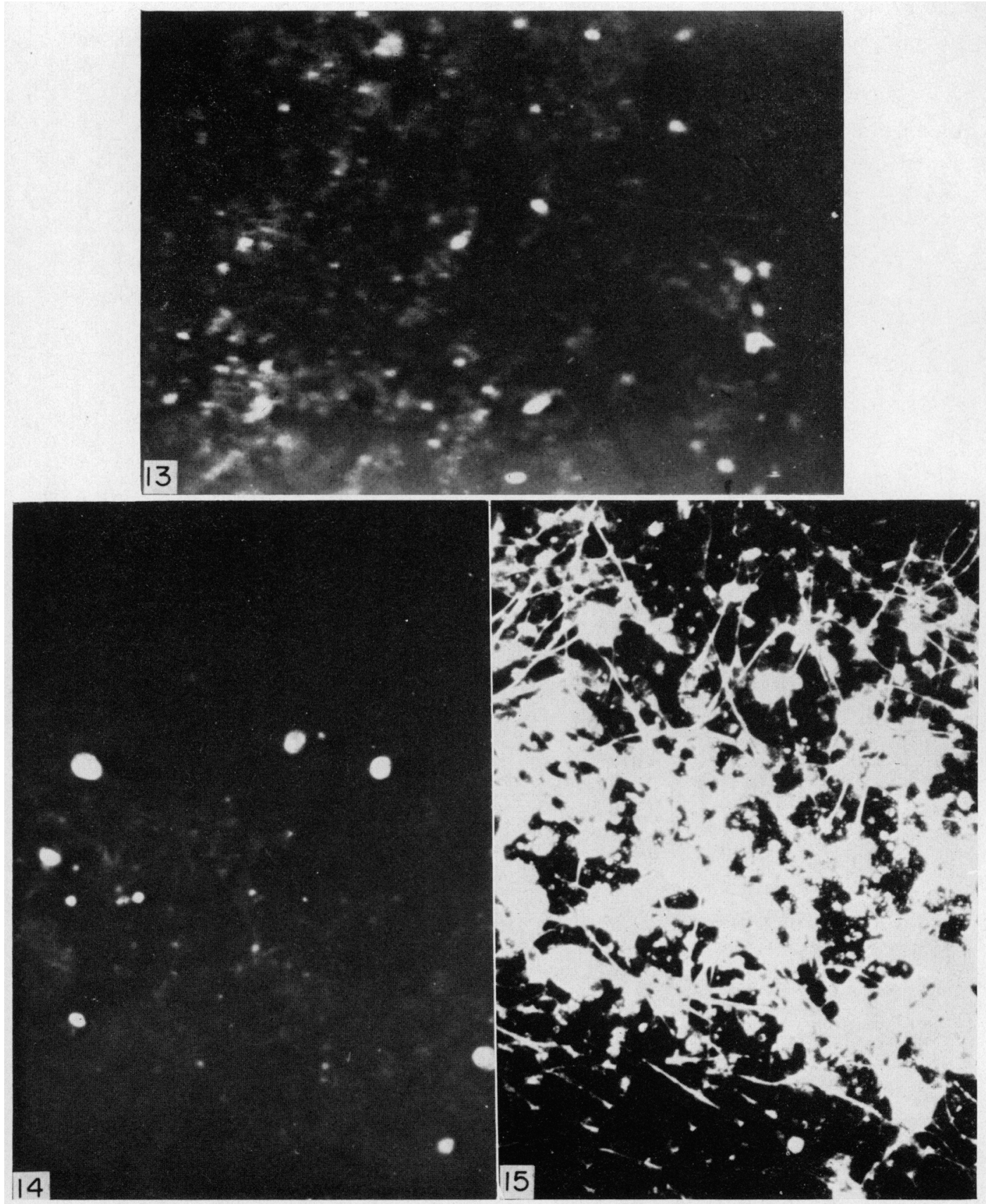

lic. 13. Immunoflueresecmer of fluorescein-labelled guinea-pig anti-rabbis iron-binding protein $;-g$ lobulin trated with mabit whole semen. $\times 1120$.

Fire 14. Immunofluerescence of fluorescein-labelled guinea-pig control $;-g$ lobulin treated with rabbit whole semen. The large bright particles are antoluoresent. $\times 1120$.

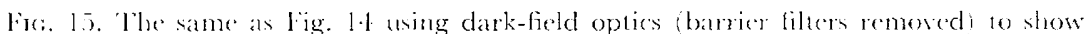
numerous spermatemoa and partietale matter $\times 1120$. Magnilieation. exposure and printing are identical lor liigs 13,14 and 13. 
not fluoresce when treated with fluorescein-labelled AIBP. The entire spermatozoon fluoresced positively with fluorescein-labelled ARWS. Seminal particles of whole semen fluoresced when treated with AIBP (Pl. 4, Fig. 13). Further evidence for the non-spermatozoan location of IBP was obtained from exchange agglutination studies (O'Rand \& Metz, 1974). In the presence of univalent (papain-digested) goat anti-rabbit whole semen, AIBP will not agglutinate ejaculated spermatozoa, but will agglutinate the seminal particles in whole semen or in seminal plasma from vasectomized males. Attempts to absorb Peak P1 to epididymal spermatozoa failed.

\section{DISCUSSION}

The iron-binding protein (IBP) isolated from rabbit ejaculates is probably a lactoferrin-like molecule. Its molecular weight and electrophoretic mobility differ from rabbit serum transferrin and rabbit milk transferrin (Baker et al., 1968). From its electrophoretic behaviour, the IBP may have some similarity to rabbit heterophil leucocyte lactoferrin (Baggiolini et al., 1970). Although the iron content of the ejaculate supernatants varied, the purification procedure gave an increase (four to six times) in the amount of iron per $\mathrm{mg}$ of protein. The SDS electrophoresis data indicate that the IBP may not be free of contaminating protein(s). Therefore, calculation of the actual iron-binding capacity of the IBP is not justified until its purity and/or sub-unit structure is firmly established.

Both lactoferrin (Masson \& Heremans, 1966) and transferrin (Quinlivan, 1968) have been identified in human seminal plasma, but neither has been localized on the spermatozoon. Absorption of anti-human seminal plasma antisera with washed spermatozoa did remove lactoferrin (Hekman \& Rumke, 1969), but did not definitely establish that the antigen was on the sperm surface because attempts to localize human lactoferrin by immunofluorescence gave ambiguous results (Hekman \& Rumke, 1969). The lactoferrin in human seminal plasma has been called 'scaferrin' (Roberts \& Boettcher, 1969) and is thought to be the sperm-coating antigen (SCA) first described by Weil \& Rodenburg (1962). The present results show that rabbit IBP is not a scaferrinlike molecule. The localization of rabbit IBP by direct immunofluorescence and exchange agglutination on seminal particles rather than on spermatozoa indicates that it is not a sperm-coating antigen.

Since the IBP has the electrophoretic mobility of a slow $\beta$-globulin and is present in seminal plasma and ejaculates but not on epididymal spermatozoa (failure to react with ARES sera) it could have been a sperm-coating protein (Weil \& Rodenburg, 1962; Weil, 1967; Roberts \& Boettcher, 1969). Contrary to what was expected, the IBP could not be localized on the spermatozoon using monospecific antisera. Because of the IBP's presence on seminal particles, pellets of six-times washed spermatozoa, which contain abundant seminal particles, will also contain IBP and any other seminal particle antigen. Thus, antisera obtained by injection of washed rabbit spermatozoa could contain antibodies against some non-spermatozoan seminal plasma antigens. This suggests that monospecific antisera should be used to localize antigens on rabbit spermatozoa. Furthermore, the use of ejaculate supernatants to obtain anti- 
seminal plasma antibodies (rather than seminal plasma from vasectomized males) may also be misleading since ejaculate supernatants may contain some sperm antigens (Chang, 1950; Metz, 1972).

Finally, it should be pointed out that these results do not argue against the concept of sperm-coating antigens, but rather against the assumption that an ejaculate supernatant antigen, not present in the epididymis, is a sperm-coating antigen. Results with cow anti-rabbit seminal plasma (Johnson \& Hunter, 1972) show that at least one seminal plasma antigen is present on the spermatozoon. The use of monospecific antisera would greatly facilitate identifying the rôle, if any, of individual sperm-coating antigens in the fertilization process. Direct evidence for a protein's presence on the sperm surface is required for its classification as a sperm-coating antigen.

\section{AGKNOWLEDGMENTS}

This paper represents contribution number 263 from the Institute for Molecular and Cellular Evolution. The research was supported by the National Institute of Health, United States Public Health Service Postdoctoral Fellowship NIH 5-Fo2-HD 53900-01 and was also aided by Population Council grant M 72.49 to Dr C. B. Metz. The helpful discussion and technical assistance of Dr J. Russo, Dr I. Russo, Dr C. Bradshaw-Sidran and Mrs F. Montes de Oca as well as the discussion and contributions to the manuscript of Dr C. B. Metz are gratefully acknowledged. Dr J. Russo kindly provided the fluoresceinlabelled goat anti-rabbit whole semen.

\section{REFERENCES}

ANDrews, P. (1965) The gel-filtration behaviour of proteins related to their molecular weights over a wide range. Biochem. F. 96, 595.

Baggiolini, M., DeMuve, C., Masson, P. L. \& Heremans, J. E. (1970) Association of lactoferrin with specific granules in rabbit heterophil leucocytes. $\mathcal{F}$. exp. Med. 131, 559.

Baker, E., Shaw, D. C. \& Morgan, E. H. (1968) Isolation and characterization of rabbit serum and milk transferrins. Biochemistry, N.Y. 7, 1371.

Ghang, M. C. (1950) Fertilization, male infertility and hyaluronidase. Ann. N.Y. Acad. Sci. 51, 1192.

Ghang, M. G. (1957) A detrimental effect of seminal plasma on the fertilizing capacity of sperm. Nature, Lond. 179, 258.

Goldman, M. (1968) Fluorescent Antibody Methods. Academic Press, New York.

Gornall, A. G., Bardawill, G. J. \& David, M. M. (1949) Determination of serum proteins by means of the biuret reaction. 7 . biol. Chem. 177,751 .

Hekman, A. \& Rumke, P. (1969) The antigens of human seminal plasma with special reference to lactoferrin as a spermatozoa-coating antigen. Fert. Steril. $20,312$.

Hudson, B. G., Ohno, M., Brockway, W. J. \& Castellino, F. J. (1973) Ghemical and physical properties of serum transferrins from several species. Biochemistry, N. Y. . 12, 1047.

HunTER, A. G. \& NorNes, H. O. (1969) Characterization and isolation of a sperm-coating antigen from rabbit seminal plasma with capacity to block fertilization. F. Reprod. Fert. 20, 419.

Johnson, W. L. \& Hunter, A. G. (1972) Seminal antigens: their alteration in the genital tract of female rabbits and during partial in vitro capacitation with beta amylase and beta glucuronidase. Biol. Reprod. 7, 332.

Keкwiск, R. A. (1940) The serum proteins in multiple myelomatosis. Biochem. 7. 34, 1248.

LI, T. S. \& BELING, C. G. (1973) Isolation and characterization of two specific antigens of human seminal plasma. Fert. Steril. 24, 134.

Masson, P. L. \& Heremans, J. F. (1966) Studies on lactoferrin, the iron-binding protein of secretions. Protides biol. Fluids, 14, 115.

MEtz, C. B. (1972) Effect of antibodies on gametes and fertilization. Biol. Reprod. 6, 358. 
Metz, C. B. \& ANIKA, J. (1970) Failure of conception in rabbits inseminated with non-agglutinating univalent antibody-treated semen. Biol. Reprod. 2, 284.

Metz, C. B., Hinsch, G. W. \& ANIKA, J. L. (1968) Ultrastructure and antigens of particles from rabbit semen. F. Reprod. Fert. 17, 195.

Metz, G. B., Seiguer, A. C. \& CASTro, A. E. (1972) Inhibition of cumulus dispersing and hyaluronidase activities of sperm by heterologous and isologous antisperm antibodies. Proc. Soc. exp. Biol. Med. $140,776$.

Morgan, E. H. \& CARTER, G. (1960) Estimation of plasma iron and total iron-binding capacity. Australas. Ann. Med. 9, 209.

O'RAND, M. G. \& METz, G. B. (1974) Tests for rabbit sperm surface iron binding protein and hyaluronidase using the "exchange agglutination" reaction. Biol. Reprod. (in press).

Ouchterlony, O. (1962) Diffusion-in-gel methods for immunological analysis II. In Progress in Allergy, Vol. 6, pp. 30-154. Eds. P. Kallos and B. H. Waksman. Karger, New York.

Postrano, V. T. \& Wiesel, L. L. (1958) A specific method for the determination of serum iron. $\mathcal{F}$. Lab. clin. Med. 52, 912.

QuinLivan, W. L. G. (1968) Analysis of the proteins in human seminal plasma. Archs Biochem. Biophys. 127,680 .

Roberts, T. K. \& Boettcher, B. (1969) Identification of human sperm-coating antigen. J. Reprod. Fert. $18,347$.

WeIr, A. J. (1967) Antigens of the seminal plasma. F. Reprod. Fert., Suppl. 2, 25.

Weil, A. J. \& Rodenburg, J. M. (1962) The seminal vesicle as the source of the spermatozoa-coating antigen of seminal plasma. Proc. Soc. exp. Biol. Med. 109, 567.

WhITAKER, J. R. (1963) Determination of molecular weights of proteins by gel filtration on Sephadex. Analyt. Chem. 35, 1950.

Williams, W. L., Abney, T. O., Ghernoff, H. N., Dukelow, W. R. \& Pinsker, M. G. (1967) Biochemistry and physiology of decapacitation factor. F. Reprod. Fert., Suppl. 2, 11.

Zappi, E., SMith, D. J. \& Shulman, S. (1972) Preparative separation of rabbit seminal plasma and immunochemical study of the resulting fractions. Int. J. Fert. 17, 145. 